\title{
bell hooks
}

\author{
City College of New York
}

\section{Linguagem: ensinar novas paisagens/novas linguagens*}

\begin{abstract}
Resumo do texto traduzido: bell hooks relaciona as opressões veiculadas pela apologia ao inglês padrão com os usos das variantes da língua inglesa nos Estados Unidos. A autora discute - lugar da linguagem nas relações de poder, especificamente nas hierarquias raciais, e propõe a ressignificação dos usos lingüísticos para a emancipação dos oprimidos.
\end{abstract}

Palavras-chave: linguagem; variantes; colonização; opressão; raça.

Copyright (c) 2008 by Revista Estudos Feministas.

${ }^{*}$ Language. Teaching New Worlds, New Words. Publicado em Teaching to Transgress: Education as Practice of Freedom. New York: Routledge, 1994. p. 167-175. Traduzido e publicado com autorização de Routledge, Inc, a division of Informa plc.
Como o desejo, a linguagem rompe, recusa-se a ser encerrada em fronteiras. Ela mesma fala contra a nossa vontade em palavras e pensamentos que se intrometem, até mesmo violam os mais secretos espaços da mente e do corpo. Foi no meu primeiro ano de faculdade que li o poema de Adrienne Rich "Os incêndios de papel em vez de crianças". Esse poema, falando contra a dominação, contra o racismo e a opressão de classe, esforça-se para ilustrar graficamente que acabar com a perseguição e tortura políticas de seres vivos é um assunto mais vital do que a censura, do que a queima de livros. Um verso desse poema deslocou e inquietou alguma coisa dentro de mim: "Esta é a língua do opressor, no entanto eu preciso dela para falar com você". Eu nunca esqueci essa frase. Talvez eu não conseguisse esquecer mesmo se eu tentasse apagá-la da memória. Palavras impõem-se, criam raízes em nossa memória contra nossa própria vontade. As palavras desse poema geraram uma vida na minha memória que eu não poderia abortar ou mudar.

Quando me pego pensando sobre linguagem agora, essas palavras estão lá, como se elas estivessem sempre esperando para me desafiar e me ajudar. Eu me pego silenciosamente recitando-as várias e várias vezes com a intensidade de um mantra. Elas me chocam, despertando-me para uma consciência da ligação entre 
línguas e dominação. Inicialmente, eu resisto à idéia da "língua do opressor", certa de que esse construto tem o potencial para desempoderar aquelas e aqueles entre nós que apenas começaram a aprender a falar, que apenas começaram a aprender a reivindicar a língua como um lugar onde nós fazemos de nós mesmos sujeitos. "Esta é a língua do opressor, no entanto eu preciso dela para falar com você". Palavras de Adrienne Rich. Então, quando li essas palavras pela primeira vez, e agora, elas me fazem pensar sobre o inglês padrão, mudar de opinião sobre aprender a falar mal da variante negra vernácula, contra o discurso rompido e partido de um povo destituído e deslocado. O inglês padrão não é a fala do exílio. É a língua da conquista e da dominação; nos Estados Unidos, é a máscara que esconde a perda de tantas línguas, todos aqueles sons da diversidade, comunidades nativas que nós nunca ouviremos, a fala do Gullah, Yiddish, e tantas outras línguas esquecidas.

Refletindo sobre as palavras de Adrienne Rich, eu sei que não é a língua inglesa que me fere, mas o que os opressores fazem com ela, como eles a moldam para se tornar um território que limita e define, como eles fazem dela uma arma que pode envergonhar, humilhar, colonizar. Gloria Anzaldúa nos faz lembrar dessa dor em Borderlands/La Frontera quando afirma: "Então, se você quer mesmo me ferir, fale mal da minha língua". Nós temos tão pouco conhecimento de como as pessoas africanas deslocadas, escravizadas ou livres, que vieram ou foram trazidas contra sua vontade para os Estados Unidos, se sentiram a respeito da perda da língua, a respeito de aprender o inglês. Somente como mulher adulta comecei a pensar sobre essas pessoas negras com relação à língua, pensar sobre seu trauma de serem forçadas a testemunhar sua língua se tornar sem sentido na cultura européia colonizadora, onde vozes julgadas estrangeiras não poderiam ser faladas, eram línguas fora da lei, fala renegada. Quando me dei conta de quanto tempo tinha levado para os americanos brancos reconhecerem as diferentes línguas dos americanos nativos, aceitarem que a fala que seus ancestrais colonizadores declararam ser meramente grunhidos ou cuinchos era de fato língua, é difícil não ouvir sempre no inglês padrão o som de massacre e conquista. Eu penso agora no pesar de africanos deslocados "sem casa", forçados a habitarem um mundo onde eles viam pessoas como eles mesmos, sob a mesma pele, a mesma condição, mas que não tinham uma língua compartilhada para falar um com o outro, que precisaram da "língua do opressor". "Esta é a língua do opressor, no entanto eu preciso dela para falar com você". Quando imagino o terror de africanos a bordo de navios 
negreiros, em conjunto para leilões, habitando a desconhecida arquitetura das plantações, eu considero que esse terror se estende além do medo da punição, que isso consiste também na angústia de ouvir uma língua que eles não poderiam compreender. O genuíno som do inglês tinha de apavorar. Eu penso nas pessoas negras se encontrando num espaço longe das culturas e línguas diversas que as distinguiam umas das outras, forçadas pelas circunstâncias a encontrar maneiras para falar umas com as outras em um "novo mundo" onde a negritude ou a escuridão da pele, e não a língua, poderia tornar-se o espaço de ligação. De que modo recordar, evocar esse terror... De que modo descrever $\circ$ que deve ter sido para os africanos, cujas ligações mais profundas foram forjadas historicamente no espaço da fala compartilhada, serem transportados abruptamente para um mundo onde o verdadeiro som da língua materna não tinha sentido...

Eu os imagino ouvindo inglês falado como a língua do opressor, no entanto eu os imagino também se dando conta de que essa língua precisaria ser possuída, tomada, reivindicada como um espaço de resistência. Imagino que o momento em que eles perceberam que a língua do opressor, tomada e falada pelas bocas dos colonizados, poderia ser um espaço de ligação foi uma intensa alegria. Nessa percepção estava a compreensão de que a intimidade poderia ser restaurada, de que uma cultura de resistência poderia ser formada de tal maneira que tornaria possível a recuperação do trauma da escravidão. Imagino, então, as pessoas africanas ouvindo pela primeira vez o inglês como "a língua do opressor" e então re-ouvindo-a como um local potencial de resistência. Aprender inglês, aprender a falar a língua estranha, era uma maneira de os escravos africanos começarem a recuperar seu poder pessoal dentro de um contexto de dominação. Possuindo a língua compartilhada, povos negros poderiam encontrar de novo uma maneira de fazer comunidade, e um sentido para criar a solidariedade política necessária para resistir.

Necessitando da língua do opressor para falar uns com os outros, eles não obstante também reinventavam, refaziam essa língua de tal modo que ela falaria além das fronteiras da conquista e da dominação. Nas bocas de africanos negros no chamado "Novo Mundo", o inglês foi alterado, transformado, e tornou-se uma fala diferente. $O$ povo negro escravizado pegou pedaços partidos do inglês e fez deles uma contralíngua. Eles colocaram junto suas palavras de tal maneira que o colonizador tivesse de repensar o significado da língua inglesa. Ainda que se tenha tornado comum na cultura contemporânea falar sobre as mensagens de resistência que emergiram na música criada 
1 Um tipo de música religiosa, originalmente desenvolvida pelos afro-americanos nos Estados Unidos.

\footnotetext{
${ }^{2}$ Neste trecho, a relação em inglês é entre as palavras nobody, no one e body.
}

por escravos, particularmente o spiritual, ${ }^{1}$ pouco foi dito sobre a construção gramatical das sentenças nessas músicas. Freqüentemente, o inglês usado nas músicas refletia o mundo destruído, rompido do escravo. Quando os escravos cantavam "nenhum corpo conhece o problema que eu vejo", seu uso da expressão "nenhum corpo" adicionava um significado mais rico do que se eles tivessem usado a expressão "ninguém", porque era o corpo do escravo que era o local concreto de sofrimento. ${ }^{2} \mathrm{E}$ ao mesmo tempo que o povo negro liberto cantava o spiritual, eles não mudavam a língua, a estrutura da sentença, de nossos ancestrais. Para cada uso incorreto de palavras, para cada colocação incorreta das palavras, era um espírito de rebelião que reivindicava a língua como um local de resistência. Usar o inglês de uma maneira que rompeu o uso e o significado padrões, de tal modo que o povo branco poderia freqüentemente não entender a fala negra, fez do inglês muito mais do que a língua do opressor.

Existe uma conexão inalterada entre o inglês mal falado do africano deslocado, escravizado e a diferente fala vernácula negra que o povo negro usa hoje. Em ambos os casos, a ruptura do padrão inglês possibilitou e possibilita rebelião e resistência. Por transformar a língua do opressor, fazer uma cultura de resistência, o povo negro criou uma fala íntima que poderia dizer muito mais do que era admissível dentro dos limites do inglês padrão. O poder dessa fala não é simplesmente possibilitar resistência à supremacia branca, mas é também fabricar um espaço para produção cultural alternativa e epistemologias alternativas - diferentes maneiras de pensar e conhecer que foram cruciais para criar uma visão de mundo contrahegemônica. É absolutamente essencial que o poder revolucionário da fala negra vernácula não seja perdido na cultura contemporânea. Esse poder reside na capacidade de o vernáculo negro interpor-se nas fronteiras e limitações do inglês padrão.

Na cultura popular negra contemporânea, a música rap tem se tornado um dos espaços onde a fala vernácula negra é usada num estilo que convida a cultura padronizada dominante para escutar - ouvir - e, em algum grau, para ser transformada. Contudo, um dos riscos dessa tentativa de tradução cultural é que isso banalizará a fala vernácula negra. Quando jovens garotos brancos imitam essa fala de uma maneira que dá a entendê-la como a fala daqueles que são estúpidos ou daqueles que estão interessados somente em diversão ou em serem engraçados, então o poder subversivo dessa fala é enfraquecido. Nos círculos acadêmicos, tanto na esfera do ensino quanto na da produção escrita, tem sido pouco o esforço feito para 
utilizar o vernáculo negro - ou, do mesmo modo, qualquer outra língua que não seja o inglês padrão. Quando, numa disciplina sobre mulheres negras escritoras que eu estava lecionando, perguntei para um grupo de estudantes etnicamente diverso por que nós ouvíamos somente o inglês padrão ser falado em sala de aula, eles ficaram momentaneamente sem palavras. Ainda que muitos deles fossem indivíduos para quem o inglês padrão era a segunda ou terceira língua, para eles simplesmente nunca tinha ocorrido que fosse possível dizer alguma coisa em outra língua, de uma outra maneira. Não é de admirar, então, que nós continuemos a pensar "Esta é a língua do opressor, no entanto eu preciso dela para falar com você".

Percebi que estava a ponto de perder meu relacionamento com a fala vernácula negra porque eu também raramente a uso nos ambientes predominantemente brancos em que eu freqüentemente estou, tanto profissionalmente quanto socialmente. E então comecei a trabalhar para integrar numa variedade de ambientes a fala vernácula negra sulista específica que eu cresci ouvindo e falando. Tem sido mais difícil integrar o vernáculo negro na escrita, particularmente para periódicos acadêmicos. Quando pela primeira vez comecei a incorporar o vernáculo negro nos ensaios críticos, os editores me enviavam de volta o trabalho em inglês padrão. Usar o vernáculo significa que a tradução para o inglês padrão pode ser necessária se se deseja atingir uma audiência mais inclusiva. No ambiente de sala de aula, eu encorajo estudantes a usarem sua primeira língua e a traduzirem, de tal modo que eles não sintam que buscar educação superior vai necessariamente afastá-los daquela língua e cultura que eles conhecem mais intimamente. Não surpreendentemente, quando, em minha disciplina sobre escritoras negras, estudantes começaram a falar usando língua e fala diferentes, estudantes brancos freqüentemente queixavam-se. Pareceu ser particularmente o caso com o vernáculo negro. Era particularmente perturbador para estudantes brancos porque eles podiam ouvir as palavras que eram ditas, mas não compreendiam o significado delas. Pedagogicamente, eu os encorajei a conceber o momento do não-entendimento do que alguém disse como um espaço para aprender. Tal espaço fornece não somente a oportunidade de escutar sem "controle/ domínio", sem possuir ou apoderar-se da fala através da interpretação, mas também a experiência de ouvir palavras não-inglesas. Essas aulas parecem particularmente cruciais numa sociedade multicultural que persiste na supremacia branca, que usa o inglês padrão como uma arma para silenciar e censurar. June Jordan faz-nos lembrar disso em On Call quando ela declara: 
Eu estou falando sobre a maioria dos problemas da linguagem no estado democrático, problemas de um valor que alguém roubou e escondeu longe e então homogeneizou numa língua "inglesa" oficial que só pode expressar não-eventos envolvendo a responsabilidade de ninguém, ou mentiras. Se nós vivêssemos num estado democrático, nossa língua poderia correr rapidamente, voar, xingar, e cantar em todos os nomes comuns americanos, todos as inegáveis e representativas vozes participantes de todas as pessoas aqui. Nós não toleraríamos a língua do poderoso e, por meio dessa, perderíamos todo o respeito pelas palavras por si mesmas. Nós faríamos nossa língua conforme a verdade de nossos muitos 'eus' e nós faríamos nossa língua conduzir-nos para a igualdade de poder que um estado democrático deve representar.

Que os estudantes do curso sobre escritoras negras estivessem reprimindo tão veementemente o ato de falar em línguas diferentes do inglês padrão sem verem essa repressão como política foi um indício da maneira como nós agimos inconscientemente, em cumplicidade com a cultura da dominação.

Discussões recentes sobre diversidade e multiculturalismo tendem a menosprezar ou ignorar a questão da língua. Críticas literárias feministas focadas em questões de diferença e vozes têm feito intervenções teóricas importantes, exigindo um reconhecimento da prioridade de vozes que são freqüentemente silenciadas, censuradas ou marginalizadas. Essa exigência da confirmação e da celebração de diversas vozes, e conseqüentemente de diversas línguas e falas, necessariamente rompe a primazia do inglês padrão. Quando defensoras do feminismo falaram pela primeira vez sobre o desejo da participação diversa no movimento de mulheres, não havia discussão sobre a língua. Era simplesmente tomado como certo que o inglês padrão permaneceria como o veículo primário para a transmissão do pensamento feminista. Agora que a audiência para a escrita e a fala feministas tornou-se mais diversa, é evidente que nós devemos mudar as maneiras convencionais de pensar sobre a língua, criando espaços onde vozes diferentes podem falar em outras palavras além do inglês ou em fala vernácula, imperfeita. Isso significa que na palestra ou até mesmo no trabalho escrito haverá fragmentos da fala que pode ou não ser acessível para todo indivíduo. Mudar a maneira como nós pensamos sobre linguagem e como nós a usamos necessariamente altera a maneira como nós sabemos o que nós sabemos. Em uma palestra onde eu possa usar vernáculo negro sulista, o dialeto oral específico da minha região, ou onde eu possa 
usar pensamentos verdadeiramente abstratos em conjunção com uma fala clara, respondendo a uma audiência diversificada, eu proponho que nós não precisemos necessariamente ouvir e saber o que é enunciado em sua totalidade, que nós não precisemos "dominar" ou conquistar a narrativa no todo, que nós possamos conhecer em fragmentos. Eu proponho que nós possamos aprender com os espaços de silêncio tanto quanto com os espaços de fala, que no ato paciente de ouvir uma outra língua nós possamos subverter esta cultura de frenesi e consumismo capitalistas que exige que todo desejo deve ser satisfeito imediatamente, ou nós possamos romper este imperialismo cultural que sugere que alguém só é digno de ser ouvido se fala em inglês padrão.

Adrienne Rich conclui seu poema com esta afirmação:

Eu estou escrevendo na máquina de escrever tarde da noite, pensando sobre hoje. Quão bem nós todas falamos. Uma língua é um mapa de nossas falhas. Frederick Douglass escreveu em um inglês mais puro do que o de Milton. Povos sofrem a preço elevado na pobreza. Há métodos mas nós não os usamos. Joan, que não podia ler, falou uma forma rural do francês. Alguns dos sofrimentos são: é duro falar a verdade; isto aqui é a América; eu não posso te tocar agora. Na América nós temos somente o presente do indicativo. Eu estou em perigo. Você está em perigo. A queima de um livro não provoca sensação em mim. Eu sei que dói queimar. Há chamas de napalm em Cantonsville, Maryland. Eu sei que dói queimar. A máquina de escrever está superaquecida, minha boca está queimando, eu não posso tocar você e esta é a língua do opressor.

Reconhecer que nós nos tocamos uns aos outros na linguagem parece particularmente difícil numa sociedade que quer que acreditemos que não há dignidade na experiência da paixão, que sentir profundamente é ser inferior; pois dentro do dualismo do pensamento metafísico ocidental, idéias são sempre mais importantes que a linguagem. Para cicatrizar a fissura da mente e do corpo, nós, povo marginalizado e oprimido, tentamos retomar nós mesmos e nossas experiências na linguagem. Nós procuramos construir um lugar para a intimidade. Incapazes de encontrar tal lugar no inglês padrão, nós criamos a fala rompida, imperfeita, desregrada do vernáculo. Quando eu preciso dizer palavras que fazem mais do que simplesmente refletir ou se dirigir à realidade dominante, eu falo o vernáculo negro. Lá, nesse lugar, nós fazemos o inglês fazer o que nós queremos que ele faça. Nós tomamos a língua do opressor 
e a viramos contra ela mesma. Nós fazemos das nossas palavras uma fala contra-hegemônica, liberando-nos nós mesmos na linguagem.

[Recebido em março de 2008 e aceito para publicação em abril de 2008]

\section{Language. Teaching New Worlds, New Words}

Abstract: bell hooks relates the oppressions, which are caused by the apology to the standard English, to the uses of the varieties from English language in the USA. The author discusses the place of language in the power relations, specifically in the racial hierarchies, and she proposes the resignification of the linguistic uses aiming at the emancipation of the oppressors.

Key Words: Language; Varieties; Colonization; Oppression; Race.

Tradução:

Carlianne Paiva Gonçalves, Joana Plaza Pinto e Paula de Almeida Silva. 